\title{
Combination ciprofloxacin and metronidazole for active Crohn's disease
}

\author{
Susan L Greenbloom MD FRCPC, A Hillary Steinhart MD FRCPC, Gordon R Greenberg MD FRCPC
}

SL Greenbloom, AH Steinhart, GR Greenberg. Combination ciprofloxacin and metronidazole for active Crohn's disease. Can J Gastroenterol 1998;12(1):53-56. Recent experimental evidence underscores the contribution of intestinal bacteria to the inflammatory process of Crohn's disease. This open study examined the efficacy and safety of combination ciprofloxacin and metronidazole for patients with active Crohn's disease of the ileum and/or colon. Seventy-two patients with active Crohn's disease of the ileum $(n=27)$, ileocolon $(n=22)$ or colon $(n=23)$ were treated with ciprofloxacin $500 \mathrm{mg}$ bid and metronidazole $250 \mathrm{mg}$ tid for a mean of 10 weeks. Clinical remission was defined as a HarveyBradshaw index of three points or less; an index reduction of at least three points indicated a clinical response. Clinical remission was observed in 49 patients (68\%), and 55 patients (76\%) showed a clinical response. A clinical response was noted in 29 of 43 patients $(67 \%)$ who were not taking concurrent prednisone treatment and in 26 of 29 patients (90\%) receiving prednisone (mean dose of $15 \mathrm{mg} /$ day). A clinical response also occurred in a greater proportion of patients with colonic disease, with or without ileal involvement $(84 \%)$, compared with patients with ileal disease alone $(64 \%)$, and in patients without resection (86\%) compared with those with previous resection $(61 \%)$. Five patients discontinued antibiotics because of adverse events. After a mean followup of nine months, clinical remission was maintained in 26 patients off treatment and in 12 patients who continued antibiotic therapy. Ciprofloxacin in combination with metronidazole is well tolerated and appears to play a beneficial role in achieving clinical remission for patients with active Crohn's disease, particularly when there is involvement of the colon.

Key Words: Antibiotic therapy, Ciprofloxacin, Combination therapy, Crohn's disease, Metronidazole

\section{Ciprofloxacine et métronidazole en association dans la maladie de Crohn évolutive}

RÉSUMÉ : De récentes preuves tirées d'une expérience clinique soulignent la contribution des bactéries intestinales au processus inflammatoire typique de la maladie de Crohn. Cette étude ouverte se penchait sur l'efficacité et l'innocuité de la ciprofloxacine et du métronidazole en association chez les patients souffrant de maladie de Crohn évolutive au niveau de l'iléon et/ou du côlon. Soixante-douze patients atteints d'une maladie de Crohn évolutive affectant l'iléon $(\mathrm{n}=27)$, l'iléocôlon $(\mathrm{n}=22)$ ou le côlon $(\mathrm{n}=23)$ ont été traités à la ciprofloxacine $500 \mathrm{mg}$ b.i.d. et au métronidazole $250 \mathrm{mg}$ t.i.d. pendant 10 semaines en moyenne. La rémission clinique a été définie comme un indice de Harvey-Bradshaw de trois points ou moins; une réduction de l'indice d'au moins trois points indiquait une réponse clinique. La rémission clinique a été observée chez 49 patients (68\%) et 55 patients (76\%) ont manifesté une réponse clinique. Une réponse clinique a été notée chez 29 patients sur $43(67 \%)$ qui ne prenaient pas de traitement à la Prednisone concurremment et chez 26 patients sur 29 (90\%) qui recevaient de la Prednisone (dose moyenne de $15 \mathrm{mg} /$ jour). Une réponse clinique a également été observée chez une proportion plus grande de patients souffrant de maladie colique avec ou sans atteinte iléale (84\%) en comparaison avec les patients qui souffraient d'atteinte iléale seulement (64\%) et chez les patients qui n'avaient pas subi de résection (86 \%) en comparaison avec ceux qui avaient subi une résection (61\%). Cinq patients ont abandonné l'antibiothérapie à cause de réactions indésirables. Après le suivi moyen de neuf mois, la rémission clinique se maintenait chez 26 patients qui n'étaient plus traités et chez 12 patients chez qui l'antibiothérapie se poursuivait. La ciprofloxacine associée au métronidazole est bien tolérée et semble favoriser la rémission clinique chez les patients qui souffrent de maladie de Crohn évolutive, particulièrement lorsqu'il y a atteinte du côlon.

Division of Gastroenterology, Mount Sinai Hospital; and Department of Medicine, University of Toronto, Toronto, Ontario

Correspondence and reprints: Dr GR Greenberg, Mount Sinai Hospital, 445-600 University Avenue, Toronto, Ontario M5G 1 X5.

Telephone 416-586-4727, fax 416-586-4802

Received for publication July 17, 1997. Accepted September 12, 1997 
$\mathrm{W}$ hether Crohn's disease is caused by a single infectious pathogen, either bacterial or viral, remains an area of continued debate. However, recent experimental evidence derived from several genetically susceptible animal models of inflammatory bowel disease lends support to the concept that normal enteric bacteria may contribute to or perpetuate the chronic inflammatory process in Crohn's disease $(1,2)$. Although antibiotics are often utilized in the management of Crohn's disease, there have been few controlled trials to support their efficacy. Metronidazole is the only antibiotic that has been shown to provide clinical benefit for patients with ileocolonic (3-5) and perianal Crohn's disease (6) and to delay the recurrence rate after ileal resection (7). Recently, observations from our centre and from other investigators suggested that ciprofloxacin alone (8) or used in combination with metronidazole (9) may be more effective than metronidazole for the treatment of perianal Crohn's disease and for selected patients with refractory intestinal Crohn's disease (10-12). These observations led us to evaluate the role of combination metronidazole and ciprofloxacin as a primary therapy for patients with active ileal and ileocolonic Crohn's disease.

We report our experience with the efficacy and safety of combination metronidazole and ciprofloxacin for the treatment of active Crohn's disease of the ileum and/or colon in 72 patients.

\section{PATIENTS AND METHODS}

Consecutive patients with radiologically and endoscopically proven active ileal and/or colonic Crohn's disease treated with the combination of ciprofloxacin $500 \mathrm{mg}$ bid and metronidazole 250 tid between 1989 and 1994 were evaluated in an open study. Patients in whom perianal disease was the major indication for treatment were excluded because their results have been reported (9). Of the 72 patients evaluated, 29 patients were receiving a mean prednisone dose of $15 \mathrm{mg} /$ day (range 5 to $30 \mathrm{mg} /$ day) and nine patients were taking oral 5-aminosalicylic acid preparations. Attempts were made to taper the dose of prednisone ( $5 \mathrm{mg}$ every second week) in patients responding to antibiotic therapy. All other medications were kept constant throughout the antibiotic treatment phase.

Disease activity was assessed by the Harvey-Bradshaw index (13). Clinical remission was defined as a HarveyBradshaw index of three or less (equivalent to a Crohn's disease activity index [CDAI] of less than 150) and a clinical response was defined as a decrease in the Harvey-Bradshaw index of at least three points (a decrease of three points is approximately equivalent to a CDAI reduction of 100 points). Clinical variables evaluated included sex, age, clinical response, concurrent drug therapy, previous use of metronidazole, location of disease, previous surgery, presence of an inflammatory mass and adverse effects of drugs. Results are expressed as mean $\pm \mathrm{SD}$. Univariate analysis used the $\chi^{2}$ test to determine clinical variables that predicted a response to antibiotic therapy. $\mathrm{P}<0.05$ was considered significant.

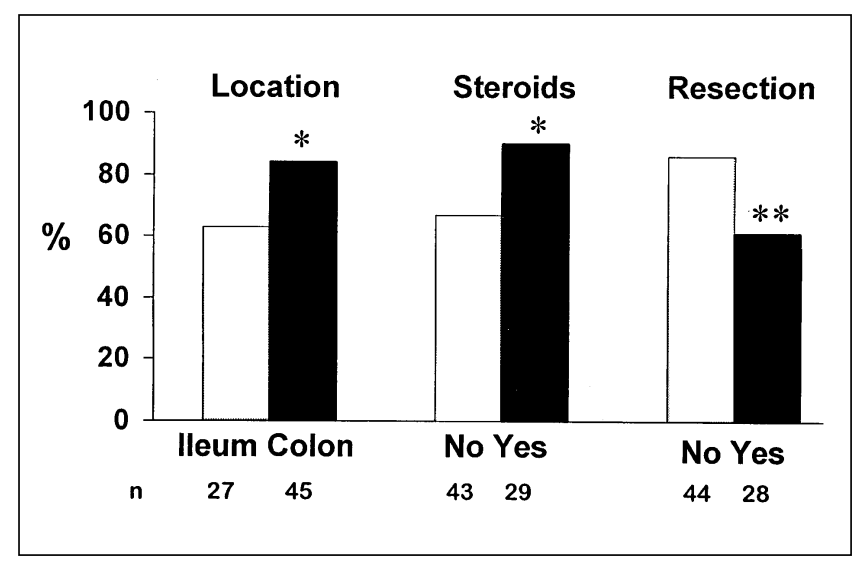

Figure 1) Percentage of patients achieving a clinical response after treatment with ciprofloxacin and metronidazole. $* P<0.05 ; * * P<0.025$

\section{RESULTS}

Seventy-two patients ( 45 female and 27 male) were treated over a five-year period; 27 patients had ileal disease, $22 \mathrm{had}$ ileal and colonic disease, and 23 had disease confined to the colon. Mean age was 32 years (range 17 to 74 ). The mean treatment period was 10 weeks (range three to 132).

After antibiotic therapy, the Harvey-Bradshaw index decreased from a pretreatment value of $6.9 \pm 3.3$ (equivalent to a CDAI of 275) to 2.0 \pm 2.3 (equivalent to a CDAI of 75). Of the 72 patients treated, 55 patients (76\%) $(95 \%$ CI $66 \%$ to $86 \%)$ showed a clinical response and 49 patients (68\%) (57\% to $79 \%$ ) achieved a clinical remission. Univariate analysis was used to assess clinical features that might predict a response to combination antibiotic therapy. There was no difference in clinical outcome between patients with colonic disease alone and those with ileocolonic disease. Thus, subsequent analyses compared patients with ileal disease alone with patients with colonic disease with or without ileal involvement (Figure 1). Seventeen of the 27 patients with ileal disease alone (63\%) (95\% CI 45\% to $81 \%$ ) responded to therapy, whereas a clinical response was noted in 38 of 45 patients with ileocolonic disease (84\%) (73\% to 95\%) $\left(\chi^{2}=4.32, \mathrm{P}<0.05\right)$. Patients with previous resections were less likely to respond than those without previous surgery. Seventeen of 28 patients (61\%) (95\% CI $43 \%$ to $79 \%)$ with resections and 38 of 44 patients (86\%) (76\% to $96 \%)$ without surgery responded to treatment $\left(\chi^{2}=6.24 ; \mathrm{P}<0.025\right)$. The majority of patients with previous resections had ileal disease - 16 of 28 patients (57\%) (95\% CI 39\% to $75 \%$ ) whereas a larger proportion of patients without resections had ileocolonic or colonic disease -33 of 44 patients ( $75 \%$ ) (62\% to $88 \%)$. Therefore, the differences between these groups may relate to disease location rather than to previous surgery $\left(\chi^{2}=7.54, \mathrm{P}<0.01\right)$.

Ten patients had an inflammatory mass of whom six responded to antibiotic treatment. Two of the four patients who did not respond had predominant obstructive symptoms and ultimately required surgery.

Of patients not receiving prednisone, 29 of 43 patients (67\%) (95\% CI 53\% to $81 \%)$ responded to antibiotic treat- 
ment. In comparison, 26 of 29 patients (90\%) (79\% to $100 \%$ ) with active disease while on prednisone responded to the addition of ciprofloxacin and metronidazole $\left(\chi^{2}=4.74\right.$, $\mathrm{P}<0.05)$; 18 patients were able to taper the dose of prednisone. Seven of nine patients receiving azathioprine responded, and nine of 10 patients who had received metronidazole alone, responded to the addition of ciprofloxacin.

Adverse effects resulting in cessation of therapy occurred in five patients. Peripheral neuropathy was observed in three patients, and in two other patients anorexia and nausea were prominent features. Noteworthy was that in all patients, the neuropathy presented within two weeks of initiation of metronidazole and resolved upon cessation of the drug. Interestingly, two of three patients who had previously reported nausea, anorexia and metallic taste with metronidazole treatment alone did not observe these same side effects after the addition of ciprofloxacin.

After a mean follow-up of nine months (range three to 36), 40 of 55 patients (73\%) who responded to treatment had discontinued therapy, and 26 patients remained in remission. Fourteen patients had a clinical recurrence after a mean of 4.5 months. Twelve of the 15 patients who were maintained on antibiotic therapy have remained in remission.

\section{DISCUSSION}

This study suggests that the combination of ciprofloxacin and metronidazole may have a beneficial effect in facilitating symptomatic remission for patients with active Crohn's disease. Clinical improvement occurred not only when the antibiotic combination was administered as a primary therapeutic modality, but also when it was given to patients who were refractory to corticosteroids. At the doses employed the two antibiotics were well tolerated and were associated with few drug-related adverse events.

Previous studies addressing the role of antibiotic therapy for active Crohn's disease have produced equivocal results. Metronidazole has been the most frequently investigated drug, and early results suggested that this agent may be most effective for patients with perianal Crohn's disease (6) and for those with disease confined to the colon (3). In a more recent trial, Sutherland and co-workers (5) confirmed that metronidazole caused significantly greater improvements in the CDAI for Crohn's patients with either ileocolitis or colitis, compared with patients with small bowel involvement alone. However, in the study by Sutherland et al the rates of complete clinical remission were similar in metronidazoleand placebo-treated patients. In one study (12), metronidazole in combination with ciprofloxacin produced $62 \%$ clinical improvement and $51 \%$ clinical remission in patients with steroid-refractory or steroid-dependent Crohn's disease; the majority of patients (84\%) had colonic involvement.

Our present study is in close accord with these findings, with an overall rate of symptomatic improvement of $76 \%$ and a symptomatic remission of $68 \%$.

Moreover, although we also found that the antibiotic combination was most effective when administered to patients with colonic involvement with or without ileal disease, one may infer from our results that a substantial portion of patients with disease restricted to the ileum will also respond to ciprofloxacin and metronidazole.

The present study was an open prospective evaluation of ciprofloxacin and metronidazole, and, therefore, subject to the limitations of this experimental design. Nevertheless, the population size does allow certain inferences regarding the potential value of this antibiotic combination and for the planning of further prospective trials. Because patients with colonic involvement seem to be more likely to show improvement compared with those with ileal disease alone, location of the disease seems to be one important variable in the assessment of response rates. As well, nonresected patients derived greater benefit than those with previous surgery, suggesting that these two subgroups may require stratification in future trials. Our initial observation that a beneficial effect occurs with metronidazole-ciprofloxacin treatment of patients with perianal disease (9) provided the rationale for extending this combination therapy to all patients with active intestinal Crohn's disease. However, preliminary data (14) on a small number of patients suggests a clinical response of $50 \%$ after ciprofloxacin in active Crohn's disease; because this value approaches the efficacy we observed with the combination therapy, further studies are required to assess whether the addition of metronidazole is required to achieve an optimal benefit.

A small randomized controlled trial (15) showed that the combination of metronidazole and ciprofloxacin was not as effective as methylprednisolone to treat active Crohn's disease. However, we found that symptomatic remission in patients receiving corticosteroids and antibiotics exceeded the value observed in patients receiving antibiotics alone. Thus, the addition of ciprofloxacin and metronidazole to corticosteroid therapy may allow lower dose, shorter duration corticosteroid treatment for active Crohn's disease. Further, although the relapse rate after withdrawal of antibiotic therapy was substantial, a small proportion of the patients who continued the antibiotic combination long term maintained remission and without adverse effects to the drugs. Therefore, sustained antibiotic therapy could contribute to a prolonged clinical remission independent of corticosteroid or immunosuppressive therapy, and requires independent evaluation.

The antibiotic combination was well-tolerated. Overall, five of 72 patients (7\%) experienced adverse effects sufficient to require withdrawal of therapy. Interestingly, peripheral neuropathy occurred in three patients within two weeks of initiation of treatment. This side effect was likely caused by the metronidazole, because we have also found similar rapid development of neuropathy in Crohn's patients treated with metronidazole alone (unpublished data). This finding contrasts results from a previous report (16) which suggested that the neuropathy related to metronidazole is a long term cumulative effect of the drug, seen only after several months of treatment. 
Nausea and anorexia are also major problems encountered with the use of metronidazole and may occur in up to $27 \%$ of Crohn's patients receiving $1 \mathrm{~g} /$ day or more of metronidazole. The lower dose of metronidazole we employed caused only a $3 \%$ withdrawal rate because of nausea, yet provided a clinical response comparable with that in other studies $(12,15)$. Thus, the utility of metronidazole $10 \mathrm{mg} / \mathrm{kg}$ or less for Crohn's patients may, in part, be enhanced with the addition of ciprofloxacin because the lower metronidazole dose reduces withdrawal rate from adverse effects without compromising clinical efficacy.

\section{CONCLUSIONS}

The combination of ciprofloxacin and metronidazole at the doses employed in this study appears to provide a beneficial effect for the symptomatic improvement of patients with active Crohn's disease. Coupled with recent observations in experimental models $(1,2,17)$ indicating an important role for enteric bacteria in facilitating the active inflammation of Crohn's disease, the present study suggests that randomized controlled trials are required to determine whether ciprofloxacin with or without metronidazole alone, and in combination with lower doses of conventional corticosteroids or the new first-pass corticosteroid budesonide (18), will induce more rapid remission in patients with active Crohn's disease. Perhaps, more importantly, trials are also required to evaluate whether long term administration of this antibiotic combination will provide benefit for maintenance of remission.

\section{REFERENCES}

1. Elson CO, Sartor RB, Tennyson GA, Riddell RH. Experimental models of inflammatory bowel disease. Gastroenterology 1995;109:1344-67.

2. Sartor RB. Insights into the pathogenesis of inflammatory bowel disease provided by new rodent models of spontaneous colitis. Inflam Bowel Dis 1995;1:64-75.
3. Ursing B, Alm T, Barany F, et al. A comparative study of metronidazole and sulphasalazine for active Crohn's disease: the cooperative Crohn's disease study in Sweden. II. Result. Gastroenterology 1982;83:550-62.

4. Ambrose NS, Allan RN, Keighley MRB, et al. Antibiotic therapy for treatment in relapse of intestinal Crohn's disease. Dis Colon Rectum 1985;28:81-5.

5. Sutherland L, Singleton J, Sessions J, et al. Double blind, placebo controlled trial of metronidazole in Crohn's disease. Gut 1991;32:1071-5.

6. Bernstein L, Brandt L, Frank M, Boley S. Healing of perianal Crohn's disease with metronidazole. Gastroenterology 1980;79:357-65.

7. Rutgeerts P, Hiele M, Geboes K, et al. Controlled trial of metronidazole treatment for prevention of Crohn's recurrence after ileal resection. Gastroenterology 1995;108:1617-21.

8. Turunen U, Farkkila M, Seppala K. Long-term treatment of perianal or fistulous Crohn's disease with ciprofloxacin. Scand J Gastroenterol 1989;24(Suppl 158):144.

9. Solomon MJ, McLeod RS, O'Connor BI, Steinhart AH, Greenberg GR, Cohen Z. Combination ciprofloxacin and metronidazole in severe perianal Crohn's disease. Can J Gastroenterol 1993;7:571-3.

10. Wolf J. Ciprofloxacin may be useful in Crohn's disease. Gastroenterology 1990;98:A212. (Abst)

11. Peppercorn NM. Is there a role for antibiotics as primary therapy in Crohn's ileitis. J Clin Gastroenterol 1993;17:235-7.

12. Prantera C, Kohn A, Zannoli F, Spimpolo N, Bonfa M. Metronidazole plus ciprofloxacin in the treatment of active refractory Crohn's disease: Results of an open study. J Clin Gastroenterol 1994;19:79-88.

13. Harvey RF, Bradshaw JM. A simple index of Crohn's disease activity. Lancet 1980;i:514.

14. Colombel JF, Lemann M, Cassagnou M, et al and the GETAID. A controlled trial comparing ciprofloxacin with mesalazine for the treatment of active Crohn's disease. Gastroenterology 1997;112:A951. (Abst)

15. Prantera C, Zannoni F, Scribano ML, et al. An antibiotic regimen for the treatment of active Crohn's disease: A randomized, controlled clinical trial of metronidazole plus ciprofloxacin. Am J Gastroenterol 1996;91:328-32.

16. Duffy LF, Daum E, Fisher SE, et al. Peripheral neuropathy in Crohn's disease patients treated with metronidazole. Gastroenterology 1985;88:681-4.

17. Jung HC, Eckman L, Yang S-K, et al. A distinct array of proinflammatory cytokines is expressed in human colon epithelial cells in response to bacterial invasion. J Clin Invest 1995;95:55-64.

18. Greenberg GR, Feagan BG, Martin F, et al and The Canadian Inflammatory Bowel Disease Study Group. Oral budesonide for active Crohn's disease. N Engl J Med 1994;331:836-41. 


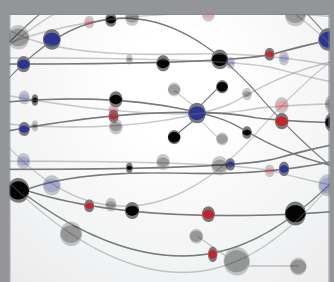

The Scientific World Journal
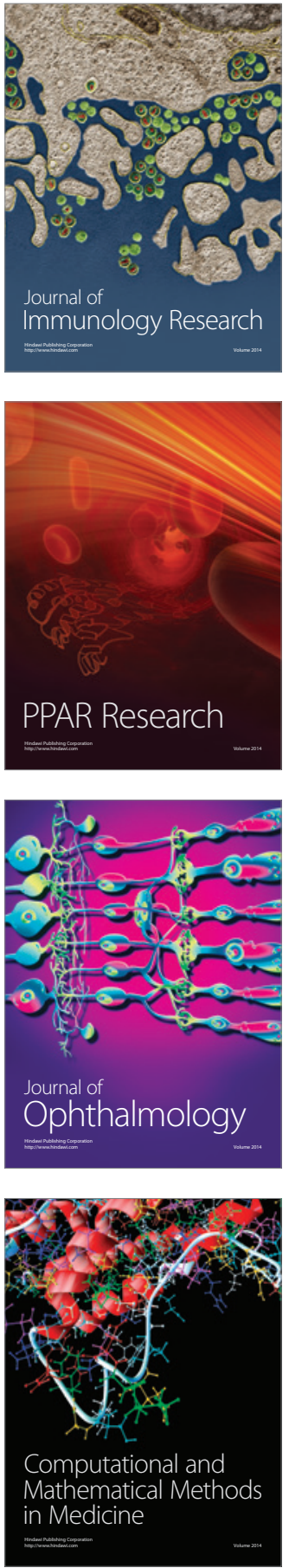

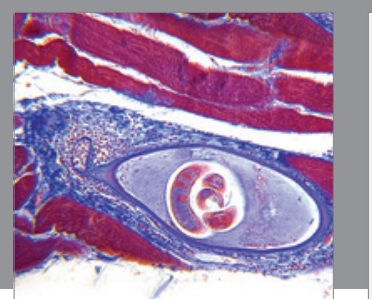

Gastroenterology Research and Practice

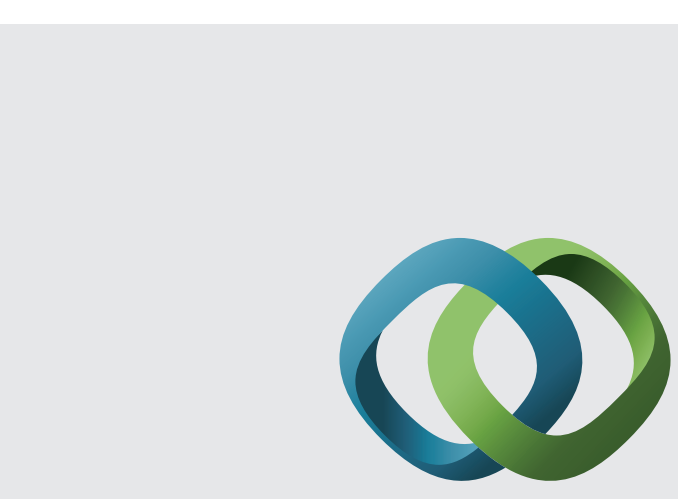

\section{Hindawi}

Submit your manuscripts at

http://www.hindawi.com
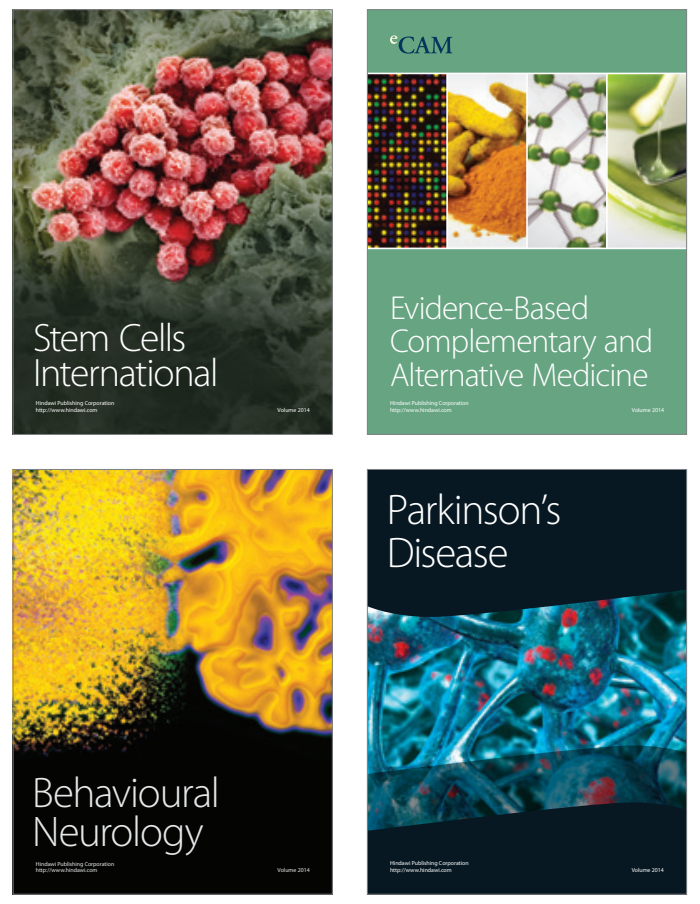
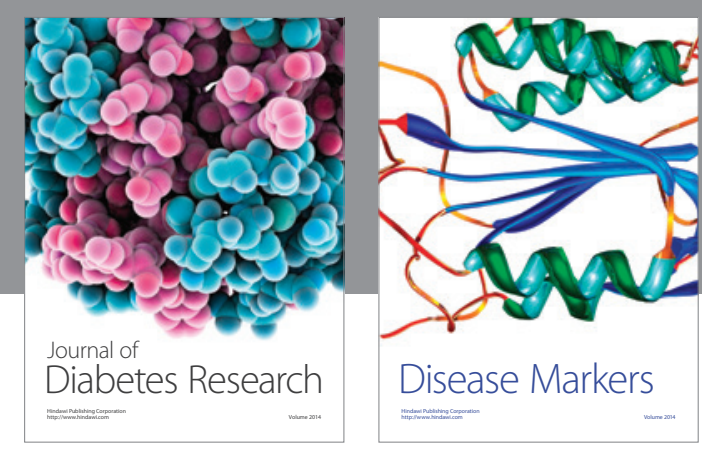

Disease Markers
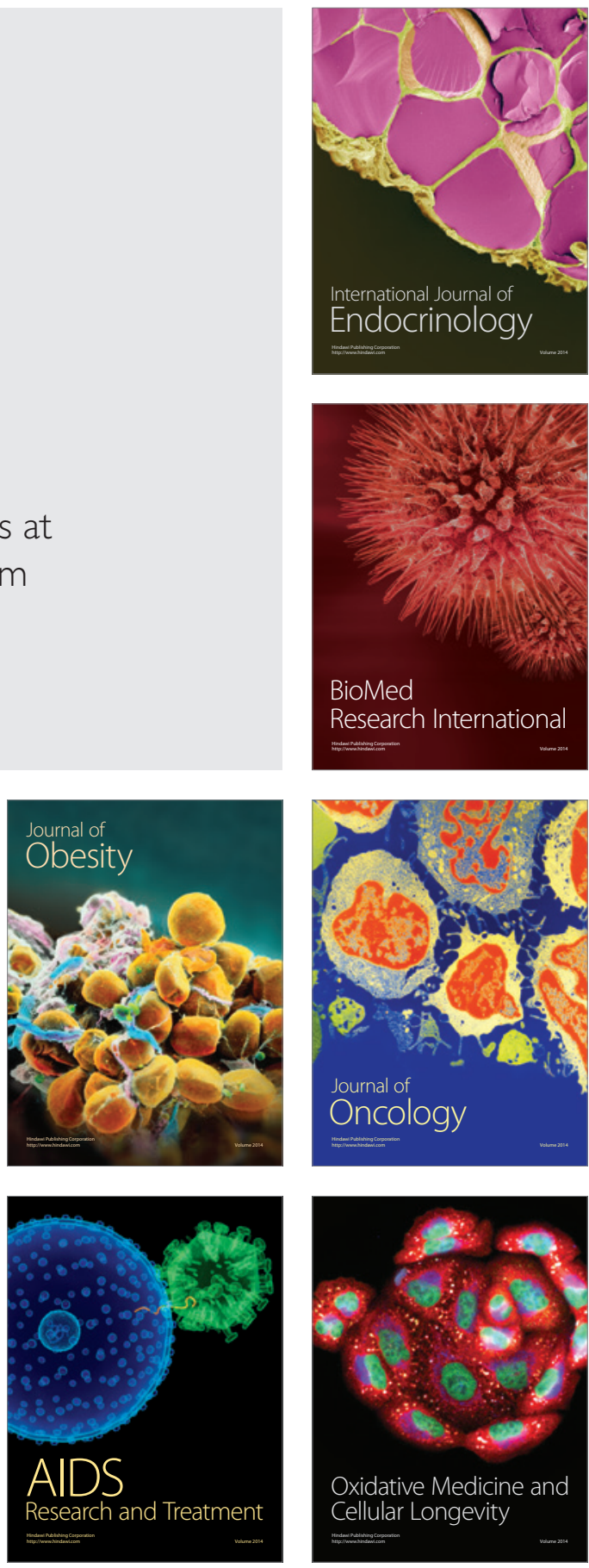